\title{
Developmental tempo in children aged 0-5 years living under unfavourable environmental conditions
}

\author{
Horacio Lejarraga, M.D. ${ }^{a}$, Diana M. Kelmansky, M.D. ${ }^{b}$ and Fernando Nunes, M.D.
}

\begin{abstract}
Objective. To describe the dynamics of development along the early years of life among children living under unfavorable socioeconomic conditions.

Population and Methods. In 5401 children younger than 6 years old living in Florencio Varela and in the Matanza-Riachuelo River Basin (Matanza, Villa 21-24, Wilde, Villa Inflamable and Acuba), areas with a high proportion of families with unmet basic needs, a logistic regression analysis was used to estimate the median age at attainment of 13 psychomotor developmental milestones; differences between these ages and median age at attainment of milestones as per the national reference were plotted on they-axis, while the median age as per thenational reference was plotted on the $x$-axis.

Results. Three stages were observed: the first one between 0 and 270 days with normal development, in which the median age at attainment was similar to that of the national reference; a second one of progressive development delay; and a third one of recovery at 1260 days. Adjusted linear spline slopes were 0.06 (not significant), $-0.26(p<0.0001)$ and 0.26 $(p<0.01)$ for stages 1,2 and 3 , respectively. The three slopes were statistically different from each other. The stage of normal development (stage 1) was attributed to the protective effect of the mother and the family environment; stage 2 of progressive delay, to the unfavorable impact of the environment, and stage 3 of partial recovery was attributed to attending a daycare center. These findings allow the implementation of effective interventions at each stage.

Conclusion. Three periods with different developmental tempos were identified.

Keywords: psychomotor development, developmental tempo, environment, preschool education.
\end{abstract}

http: / / dx.doi.org/10.5546/ aap.2018.eng.e210

To cite: Lejarraga H, Kelmansky DM, Nunes F. Developmental tempo in children aged 0-5 years living under unfavorable environmental conditions. Arch Argent Pediatr 2018;116(2):e210-e215.
Funding:

Data collection was

funded by the Matanza-

Riachuelo River Basin

Authority.

\section{Conflict of interest:}

None.

Received: 04-10-2017

Accepted: 09-10-2017

\section{INTRODUCTION}

Unfavorable environmental conditions are associated with a delay in the child's development over the early years of life. This is observed both in our country ${ }^{1}$ and worldwide. ${ }^{2}$

Yet, there is not enough information on whether this effect is constant during the early years of life, produces a progressive or occasional delay, affects the maturing tempo (the speed with which the child achieves development milestones), is installed from birth or appears later in life and if it is reversible in the face of occasional changes in the environment. To answer these questions it would be necessary to carry out a longitudinal study; however, there is valuable cross-sectional information about child development in unfavorable environments at different ages, and with the results obtained, it is feasible to make an accurate description and develop a hypothesis.

From a Gesellian perspective, ${ }^{3}$ child development can be studied by measuring the age in which children achieve certain milestones and compare it with the age for milestone achievement among healthy children, that is, the national reference (NR). ${ }^{4}$ The speed with which a child reaches one milestone after another one is called developmental tempo. The questions that this study intends to answer are the following: do children aged 0 to 6 years old with unmet basic needs and development delay have, during the first 6 years of life, the same developmental tempo or can periods with different tempos be identified? Does a developmental delay start at birth or at older ages? Are there, perhaps, periods of recovery from this delay?

The main objective of this paper is to answer these questions. 


\section{MATERIAL AND METHODS}

\section{Surveys and samples}

The study was carried out with data obtained from several surveys which are detailed below in reference 1 .

The Study on Nutrition, Psychomotor Development and Toxicological Analysis II (Estudio de Nutrición, Desarrollo Psicomotor y Análisis Toxicológico II, ENUDPAT II) was conducted in 2012 with the aim of comparing and assessing the differences between La Matanza (LM), a municipality in the MatanzaRiachuelo River Basin, and Florencio Varela $(\mathrm{FV})$, a municipality that does not belong to said area. LM has 1775816 inhabitants and FV, 426005 . Neighborhoods with a high prevalence of families with unmet basic needs (UBNs) were selected. Among the samples of the study, 80.3\% of households in LM and $76.8 \%$ of FV had, at least, one UBN. 999 and 1181 children younger than 6 years old were studied, respectively. ${ }^{1}$

The other four surveys were performed on the total population younger than 6 years old from each selected shantytown: ${ }^{1}$ Wilde (698 children), Acuba (1037), Villa Inflamable (628) and Villa 2124 (958), all of them part of the Matanza-Riachuelo River Basin. In each survey, each household was visited so that objectives were clearly described and people were encouraged to participate; after the informed consent was signed, the anthropometric, toxicological, nutritional and childbearing survey was conducted and the National Screening Test (Prueba Nacional de Pesquisa, PRUNAPE) ${ }^{5}$ was implemented to detect non-apparent development disorders, with a high specificity and sensitivity.

In each area, qualified survey takers assessed, in each child, the achievement of 13 milestones, selected out of the total of 79 milestones available at the National Reference (NR), based on 3573 healthy children from across Argentina. ${ }^{4}$

The selected milestones are described below, each one followed by the median age (MA) at attainment in days according to the NR: smiles responsively (33 days), searches for sound with the eyes (142), head steady (33), searches an object (226), pincer grasp (277), walks well (376), daytime bladder control (767), combines words (693), completes phrases (829), recognizes three colors (1209), heel-to-toe walk (1318), copies a cross (1340), draws a person with 6 parts (1534). These are the same milestones selected to develop positive health indicators ${ }^{6}$ and to assess their relationship with social and biological determinants of health. ${ }^{7}$

\section{Estimate of the median age of achievement}

Median (percentile 50) ages of achievement of each milestone that were estimated in a former study with logistic regression were used, according to the previously described method. ${ }^{6}$ The logistic curve obtained from the equation $\mathrm{y}=1 / 1(1+\exp (-\mathrm{a}-\mathrm{b} \mathrm{x}))$ was adjusted with the outcome measure (response) " $y$ " (the child attained or did not attained the milestone) and the independent outcome measure $x=$ age. The median age (MA), that is to say, the age at which $50 \%$ of children achieved the milestone $(p=0.5)$, was obtained with the following equation:

$$
\mathrm{MA}=-\mathrm{a} / \mathrm{-b}
$$

The degree of data adjustment to the model was evaluated with the Hosmer-Lemeshow and the deviance tests. ${ }^{8}$ In all the areas and milestones, an adequate adjustment was found, except for two milestones in Acuba, which were not included. By having the MA at attainment of all the milestones in each area, the difference (D) between this age and the age at attainment of each milestone as per the NR was obtained. Then, a linear regression was estimated based on the $\mathrm{D}$ model $=\mathrm{a}+\mathrm{b} \mathrm{x}$, where " $\mathrm{D}$ " was the difference between the age at attainment of each milestone in the children studied and in the NR; " $x$ " was the MA at attainment of the milestone as per the NR; " $b$ " was the regression coefficient (the slope of the straight line); i.e., the development trend (DT).

Differences between the MA at attainment of each milestone and the NR were plotted against the age at attainment as per the NR. Based on simple observations, the different ages in which there seemed to be trend changes were identified and, taking these points into account, adjacent milestone groups bearing a similar trend were analyzed separately. Three trends were identified: a first group in the first 270 days of life, another one between 270 and 1260 days of life, and a third one as of 1260 days onward. Then a multiple regression model was adjusted to obtain a linear piecewise model with two nodes in 270,1260 including the area as a control factor to avoid confounding effects related to the area. This adjustment resulted in linear segments (phases) on each group of milestones that spliced on each node and allowed to estimate the slope and significance of differences among the three slopes.

So as to investigate the cause of the positive trend of the third segment, the PRUNAPE test results were studied among children who attended or did not attend a daycare center. The differences in the rate of children who passed or 
failed the PRUNAPE test depending on whether they attended or not a daycare center were assessed with the $\chi^{2}$ test.

\section{RESULTS}

Figure 1 shows the differences between the MA at attainment of each milestone in the studied children and the corresponding one as per the $N R$, in each of the five areas evaluated. Area names were replaced by numbers to safeguard their identity.

The five areas show a similar trend: the first milestones differ a little from the NR; then, there is a descending slope indicating a progressive delay for the achievement of milestones up to a point (observed in all the areas) in which this trend is reverted: the last milestones (one or two) are invariably achieved earlier than expected according to the trend of the second slope. The trend is similar in the five areas, regardless of the type of milestone (language, motor functions, etc.).

Based on these results, data of the five areas were grouped in a single figure (Figure 2). Since the outcome measure "area" was not significant in the multiple regression analysis, an adjustment (linear spline regression) was done excluding this outcome measure from the model. This rendered higher statistical power and allowed to evaluate the existence of significant differences among slopes, with the five areas grouped in a single sample.

Results are shown in Figure 2.

Regression straight lines clearly show the three development stages: a first stage of normal development with the achievement of early milestones at the same age as the NR; a second stage, with progressive delay for milestone attainment (a maturing tempo slower than average); and a third stage with a change in the

FIGURE 2. Differences between the MA at attainment of the developmental milestones in each of the five areas and those of the NR (Ref. 5)

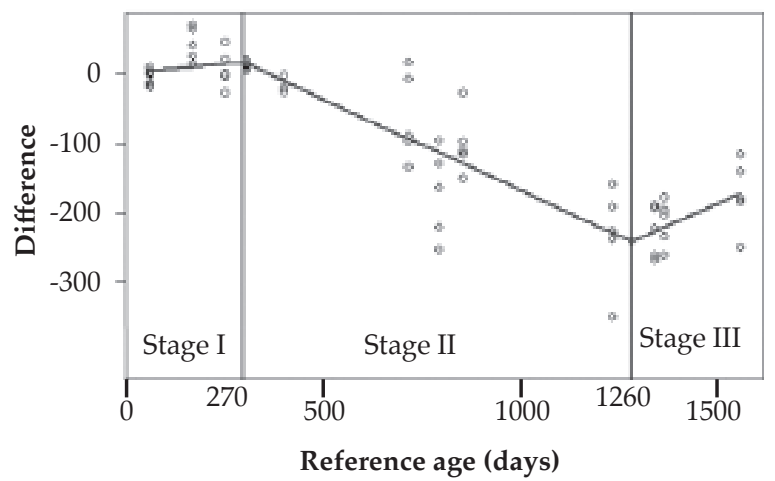

FIGURE 1. Differences between the median ages at attainment of the developmental milestones in all five areas of the MatanzaRiachuelo River Basin and those of the National Reference (Ref. 5)

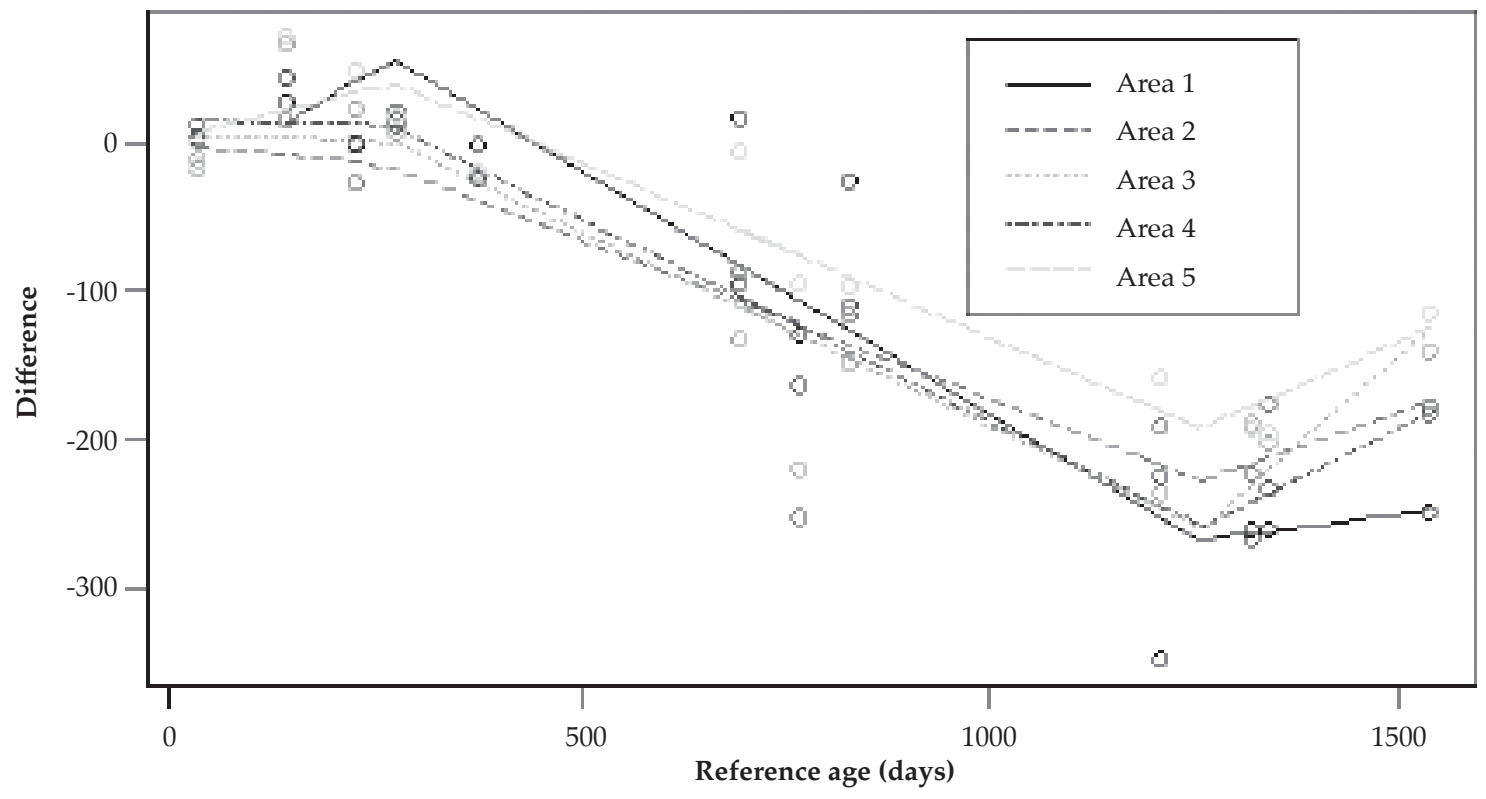


trend: children accelerate their maturing tempo and revert the trend towards delay, with partial recovery.

Stage 1 slope is not statistically different from zero; and those of stages 2 and 3 are significant, though the slope of stage 2 is negative and that of stage 3 is positive. Differences among slopes of the 3 consecutive segments are statistically significant. Coefficients are shown in Table 1.

Differences among slopes ( 0.32 between stage 1 and stage 2, and 0.518 between stage 2 and stage 3 ) are statistically significant ( $p: 0.0019$ and $<0.00001$, respectively).

These results were compared with those obtained at the PRUNAPE test in several studies, ${ }^{1,9}$ as shown on Table 2 . There is a growing trend regarding the proportion of children who fail the PRUNAPE test, up to 4 years old, when this trend reverts.

TABLE 1. Regression coefficients and statistical significance of straight lines adjusted to the three observed stages

\begin{tabular}{lcc}
\hline Stage & Estimated slope & $\boldsymbol{P}$ value \\
\hline 1 & 0.058 & 0.50 \\
2 & -0.262 & $<0.00001$ \\
3 & 0.256 & 0.009 \\
\hline
\end{tabular}

Table 3 reviews the relationship between the proportion of children who failed the PRUNAPE test and the attendance to kindergarten or a daycare center. The 0- to 2-year-old groups do not show remarkable differences with the trend of failing or passing the PRUNAPE test, but there is a statistically significant association in the group of children older than 3 years old between the attendance to kindergarten and a lower rate of failure of the PRUNAPE test.

\section{DISCUSSION}

In the present study, in all places examined, three stages of psychomotor development have been found in children up to 6 years old. There is a first stage of normal development attributable to the protection that the mother and the family exert over the child. Then, there is a second stage of progressive developmental delay, consisting in a slowing down of the maturing tempo. During this stage, there is a progressively increasing interval between the achievement of a milestone and the next one. The third stage states the acceleration of the developmental tempo. The concept of tempo is not original; it was used for the first time by Gesell in $1946^{10}$ and later by Tanner, ${ }^{11}$ both with the same sense given in this

TABLE 2. Prevalence of children who fail the National Screening Test by age groups

\begin{tabular}{lcccc}
\hline & \multicolumn{2}{c}{ ENUDPAT I* $^{*}$} & \multicolumn{2}{c}{ SAN ISIDRO $^{* *}$} \\
\hline Age range (years) & $\mathbf{N}$ total & Failed the PRUNAPE test & N total & Failed the PRUNAPE test $^{\text {N }}$ \\
\hline $0-0.99$ & 232 & $\mathbf{N}(\%)$ & $\mathbf{N}$ & $\mathbf{N}(\%)$ \\
$1.0-1.99$ & 253 & $34(14.0)$ & 244 & $7(2.9)$ \\
$2.0-2.99$ & 232 & $55(21.7)$ & 183 & $18(2.7)$ \\
$3.0-3.99$ & 196 & $99(21.7)$ & 116 & $33(28.4)$ \\
$4.0-4.99$ & 234 & $104(44.3)$ & 112 & $45(40.2)$ \\
$5.0-5.99$ & 197 & $65(33.0)$ & 107 & $45(42.1)$ \\
Total & 1344 & $455(33.9)$ & 839 & $22(28.6)$ \\
\end{tabular}

ENUDPAT: Study on Nutrition, Psychomotor Development and Toxicological Analysis (Estudio de Nutrición, Desarrollo Psicomotor y Análisis Toxicológico); PRUNAPE: National Screening Test (Prueba Nacional de Pesquisa)

${ }^{*}$ ENUDPAT I. ${ }^{1}$

** San Isidro. ${ }^{9}$

TABLE 3. Proportion of children who failed the National Screening Test (Comprehensive Health Assessment in Areas of Risk at the Shantytown,21-24 908 children aged 0 to 5 years old) depending on whether they attend or not kindergarten or a daycare center ${ }^{6}$

\begin{tabular}{lccccccc}
\hline Age group & \multicolumn{2}{c}{ Does not attend a daycare center } & \multicolumn{2}{c}{ Attends a daycare center } & Total \\
\hline & \multicolumn{3}{c}{ Failed the PRUNAPE test } & \multicolumn{3}{c}{ Failed the PRUNAPE test } \\
\hline $0-2.99$ años & Total & $\mathbf{N}$ & $\%$ & Total & $\mathbf{N}$ & $\%$ & \\
$3.0-5.99$ años & 417 & 110 & 26.4 & 267 & 56 & 21.7 & 684 \\
\hline
\end{tabular}

$\chi^{2}=98,1 ; \mathrm{p}<0.00001$.

PRUNAPE: National Screening Test (Prueba Nacional de Pesquisa). 
study, and it refers to the speed at which the child progresses towards the adult state. In the case of development, a slower tempo means a progressive delay in the sequential achievement of milestones with respect to the NR.

Our results can be better assessed by previous studies conducted with other methods. If the first stage really expresses a normal development during the first year, then the prevalence of delays in this age range should be low. If the slope of stage 2 of progressive delay is real, then there should be a progressive increase in delays between 2 and 4 years old; and, if there is really an ascending slope in the developmental tempo, the prevalence of delays should decrease in the fifth year of life. Table 2 accurately shows these results in previous studies conducted in three health care centers in San Isidro ${ }^{9}$ and in the MatanzaRiachuelo River Basin, called ENUDPAT I. ${ }^{1}$ The PRUNAPE test was administered in both places; this is a screening tool with a positive predictive value of $94 \%$, which makes it a reliable indirect indicator of developmental disorders. In Table 2 , the prevalence during the first year of life is low in ENUDPAT I and very low in San Isidro. This low prevalence is consistent with stage 1 of trends in Figure 2. Then, up to 4 years old, there is a growing proportion of children who fail the PRUNAPE test, which is consistent with stage 2 in Figure 2. However, at 5.00-5.99 years old, this prevalence decreases and is lower than 4 years old in each of the cases. This may be due to the positive impact that attending kindergarten or a daycare center can have on the child's development at a given age.

This latest piece of information was assessed by reviewing studies conducted in the same areas of the Matanza-Riachuelo River Basin, with the same children from whom results shown in Table 3 were obtained. In this table a strong association is observed between attending kindergarten and the low rate of failure of the PRUNAPE test.

The normality in the age at attainment of developmental milestones in the first months of life can be accounted for based on the knowledge about the protective effect that the mother and the family setting has on the possible negative effects of the environment along these early months. In our country, results of the HOME test in the first year of life compared with that conducted by O’Donnell et al. in Tierra del Fuego at a later date, support this hypothesis. ${ }^{12}$

After the first year of life, both the mother and the family setting are not enough to protect the child from an unfavorable environment, and this begins to exert an increasingly strong effect on the child, who starts undergoing a delay. Structural variables associated with this delay are the maternal socioeconomic and educational level which act through already described intermediate variables such as poor sanitary conditions, lack of access to drinking water, lack of sewer systems, low birth weight, frequent infections and hospitalizations, iron deficiency anemia, environmental contamination or pollution, etc. ${ }^{1}$

The acceleration of developmental tempo after 4 years old can be attributed to attending kindergarten or a daycare center, hypothesis that should be investigated more thoroughly, considering its fundamental social and educational significance. Further studies should be conducted to look into social variables associated with attending kindergarten and to discriminate if it relates to attending kindergarten or a daycare center, whose objectives and work dynamics are different. Fortunately, the Early Education Act has been enacted in our country and consequently, attending kindergarten is compulsory from the age of $4,{ }^{13}$ a measure that can have a very effective impact on the development of children nationwide.

It is interesting to know that there are other evolutionary models described in different developmental disorders. Longitudinal studies have shown that there are children exhibiting a delay from birth, who then keep a normal tempo, i.e. the interval between the age at attainment of one milestone and the next one is constant. Other models, described by Bishop et al., among children in the north of England, aged 3 to 5 years old with non-specific language impairment, ${ }^{14}$ show an early development normality followed by an impairment from a certain age also described among children with autism. ${ }^{15}$

No similar descriptions about changes in development trends along the early years of life have been found in the literature, but the three stages described favor the development of effective interventions for each of them. To confirm our hypothesis about factors associated to these changes, it will be necessary to conduct a longitudinal study; in the meantime, pediatric and public health implications of these findings are very important: in the first year, family structure should be strengthened, and breastfeeding and maternal outcomes should be protected. In the 1-4 year period, social and biological determinants associated with the development delay, already 
described in detail in previous publications, must be counteracted, ${ }^{1}$ and, in order to favor the third stage, ensure that all 4-year-old children attend kindergarten nationwide. All of the above must be carried out with the surveillance of development from an epidemiological standpoint, in order to assess the findings and interventions described.

\section{Acknowledgments}

We thank members of Acumar team working between 2010 and 2014 who helped us obtain supporting data about the Matanza-Riachuelo River Basin: Ivan Insúa, Cecilia Pascucci, Alicia Masautis, Celina Lejarraga, Gabriela Charrúa.

\section{REFERENCES}

1. Lejarraga H, Pascucci MC, Masautis A, et al. Desarrollo psicomotor infantil en la Cuenca Matanza-Riachuelo. Pesquisa de problemas inaparentes del desarrollo. Rev Argent Salud Pública 2014;5(19):17-24.

2. Committee on Nervous System Disorders in Developing Countries. Neurological, Psychiatric and Developmental Disorders. Washington DC: National Academic Press; 2000. [Accessed on: April 6 ${ }^{\text {th }}$, 2017]. Available at: http//www. nap.edu/catalog//10111.html.

3. Lejarraga H. Cinco perspectivas para el estudio del desarrollo. In: Desarrollo del niño en contexto. Buenos Aires: Paidós; 2004. Pages 41-66.

4. Lejarraga H, Krupitzky S, Kelmansky D, et al. Edad de cumplimiento de pautas de desarrollo en niños argentinos menores de seis años. Arch Argent Pediatr 1996;94(6):355-67.
5. Lejarraga H, Kelmansky DM, Pascucci MC, et al. Prueba Nacional de Pesquisa (PRUNAPE). Buenos Aires: Fundación Hospital Garrahan; 2004.

6. Lejarraga H, Kelmansky D, Pascucci MC, et al. Assessment of child psychomotor development in population groups as a positive health indicator. Arch Argent Pediatr 2016;114(1): 23-9.

7. Lejarraga H, Pascucci MC, Krupitzky S, et al. Psychomotor development in Argentinean children aged 0-5 years. Paediatr Perinat Epidemiol 2002;16(1):47-60.

8. Hosmer DW, Lemeshow S. Applied logistic regression. New York: Wiley; 1989.

9. Lejarraga H, Menéndez A, Menzano E, et al. PRUNAPE: Pesquisa de trastornos de desarrollo en el primer nivel de atención. Arch Argent Pediatr 2008;106(2):119-25.

10. Gesell A. The constancy of psychomotor tempoinindividual infants. J Genet Psychol 1940;57:445-50.

11. Tanner JM. Developmental age, and the problems of early and late maturers. In: Foetus into Man: physical growth from conception to maturity. Cambridge, Mass: Open Books; 1978. Pages.78-86.

12. O’Donnell A, Carmuega E. Proyecto Tierra del Fuego Encuesta sobre desarrollo infantil. Buenos Aires: CESNI; 1996.

13. Argentina. Ley de Educación Nacional 26.206. Buenos Aires, 27 de diciembre de 2006. [Accessed on: September 19 $\left.{ }^{\text {th }}, 2017\right]$. Available at: http:/ / servicios.infoleg.gob.ar/ infolegInternet / anexos / 120000-124999/123542/norma. htm.

14. Bishop DV, Edmundson A. Specific language impartment as a maturational evidence from longitudinal data on language and motor development. Dev Med Child Neurol 1987;29(4):442-59.

15. Landa R, Garrett-Mayer E. Development in infants with autism spectrum disorders: a prospective study. J Child Psychol Psychiatry 2006;47(6):629-38. 